decade of age) and lower LVEF (0.94 (0.89 to 0.99) for each $10 \%$ increase) were independent risk factors for azotaemia

For severe hyperkalaemia (serum potassium $>6.0$ $\mathrm{mmol} / \mathrm{l}$ ) we added to the model baseline serum creatinine concentration and whether the patient was taking potassium supplementation. In this analysis the NYHAFC (3.36 (1.17 to 9.69) for each class) and lower LVEF $(0.37$ (0.15 to 0.95$)$ for each $10 \%$ increase) were predictive factors.

\section{Comment}

Taking spironolactone for congestive heart failure is associated with considerably more frequent side effects than previously thought. ${ }^{1}$ Age, lower LVEF, and higher NYHAFC are predictors of hyperkalaemia and azotaemia.

Excessive diuresis might be an important cause of renal dysfunction while taking spironolactone. One way of dealing with renal dysfunction secondary to spironolactone may be to reduce doses of concomitant diuretics.

In the future, drugs such as eplerenone may replace spironolactone, but the risks of hyperkalaemia and renal insufficiency may be equally high. ${ }^{5}$ We found that adverse effects with spironolactone were common. We recommend that particular caution is taken in elderly people with LVEFs below $20 \%$, potassium supplementation should be discontinued, changes in body weight should raise concern, doses in concomitant diuretic regimens may need adjustment, and continuous laboratory monitoring remains inevitable.

We thank P H Nielsen, H Bartholdy, I Henriksen, and L Flye Jensen.

Contributors: FG, SG, PRH, and DA designed the study. MS collected the data. All authors did the analysis and formulated the results and discussion. MS wrote the first draft of the manuscript, and FG, SG, PRH and DA contributed to later editions. All authors reviewed the final version of the manuscript. $\mathrm{DA}$ is guarantor.

Funding: Merck, F Hoffmann-La Roche Ltd, Research Fund of the Copenhagen Hospital Corporation, Elisabeth M Schlinsog's Fund, Danish Hospital Foundation for Medical Research, and Danish Heart Foundation.

Competing interests: None declared.

Ethical approval: Ethics committee of the Frederiksberg and Copenhagen communities.

1 Pitt B, Zannad F, Remme WJ, Cody R, Castaigne A, Perez A, et al The effect of spironolactone on morbidity and mortality in patients with severe heart failure. N Enol J Med 1999:341:709-17. (1 tone Evaluation Study Investigators.)

2 Greenberg B. Treatment of heart failure: state of the art and prospectives. J Cardiovasc Pharmacol 2002;38:59-63.

3 Remme WJ, Swedberg K. Comprehensive guidelines for the diagnosis and treatment of chronic heart failure. Eur J Heart Fail 2002;4:11-22 (Task force for the diagnosis and treatment of chronic heart failure of the European Society of Cardiology.)

Galatius S, Gustafsson F, Nielsen PN, Atar D, Hildebrandt PR. An integrated approach to diagnosis and therapeutic management of patients with systolic heart failure in the Copenhagen metropolitan area. Am Heart J 2002;144(suppl):S2.

Pitt B, Remme W, Zand F, Neaton J Gatlin M, Roniker B, et al. A double-blind, randomized, placebo-controlled trial evaluating the safety double blind, rache and efficacy of eplerenone in patients with heart fallure following acute myocardial infarction. N EnglJ Med 2003,348.1309-21. (Eplerenone PosAMI Heart Failure Efficacy and Survival Study.) (Accepted 7 August 2003)

\title{
Increasing hospital admissions for systemic allergic disorders in England: analysis of national admissions data
}

Ramyani Gupta, Aziz Sheikh, David Strachan, H Ross Anderson

Department of Community Health Sciences, St George's Hospital Medical School, Cranmer Terrace, London SW17 0RE Ramyani Gupta Lung and Asthma Information Agency epidemiologist Aziz Sheikh NHS/PPP national primary care post doctoral fellow David Strachan professor of epidemiology H Ross Anderson professor of epidemiology and public health

Correspondence to: R Gupta

roupta@

sghms.ac.uk

BMJ 2003;327:1142-3
Epidemiological studies indicate that the prevalence of allergic disorders such as allergic rhinitis, asthma, and eczema have increased during recent decades in many Western countries. ${ }^{1}$ Although anecdotal reports suggest that the prevalence of systemic allergic conditions may also be changing, only limited evidence exists to support this assertion. ${ }^{2}$ We report on trends in admissions for anaphylaxis, angio-oedema, food allergy, and urticaria, analysed by using national hospital discharge statistics from 1990-1 to 2000-1.

\section{Methods and results}

We obtained hospital admissions data from the hospital episode statistics system. ${ }^{3}$ This database records episodes of care after admission to hospital and assigns a primary diagnosis on discharge based on the international classification of diseases (ICD). ${ }^{4}$ Data are available by financial year (1 April-31 March). Diagnoses were classified using the ninth revision (ICD-9) up to March 1995 and using the tenth revision (ICD-10) thereafter.
We identified admissions for anaphylaxis, angiooedema, food allergy, and urticaria (ICD-9 codes: 995.0, 999.4, 995.1, 693.1, 708; ICD-10 codes: T78.0, T78.2, T80.5, T88.6, T78.3, L27.2, T78.1, L50). We calculated age and sex standardised admission rates and used rate ratios to quantify the changes over the 11 year period. We tested for time trend by fitting simple linear regression models to the standardised rates for each condition.

A total of 49300 admissions for systemic allergic conditions occurred during the 11 year study period (urticaria: 19 250; anaphylaxis: 13 230; food allergy: 8690; angio-oedema: 8180). Total admissions for these four disorders increased from 1960 admissions in $1990-1$ ( $0.02 \%$ of all admissions) to 6752 in $2000-1$ $(0.06 \%)$ (figure).

The largest increases in rates have been for anaphylaxis and food allergy. Anaphylaxis rates rose from 6 to 41 per million between 1990-1 and 2000-1, and food allergy rates rose from 5 to 28 per million over this period. The greatest number of admissions was for urticaria, although increases in admission rates 


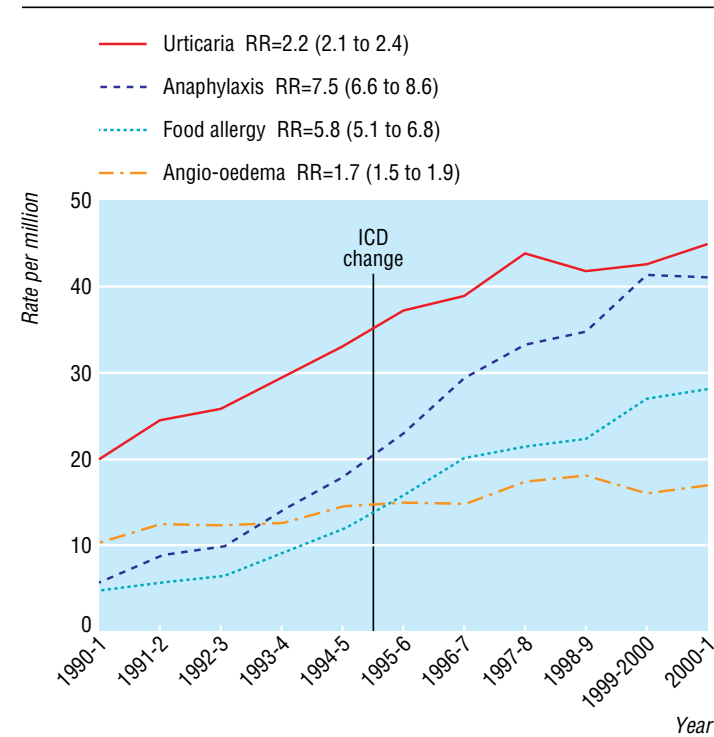

Trends in age and sex standardised admission rates for anaphylaxis, angio-oedema, food allergy, and urticaria, with rate ratios (RR) and 95\% confidence intervals, England 1990-2001

for this condition have been less rapid, doubling from 20 to 43 per million. Admissions for angio-oedema have risen more modestly from 10 to 17 per million. All trends were highly significant $(\mathrm{P}<0.0001)$.

\section{Comment}

Highly significant increases in admissions for systemic allergic diseases (anaphylaxis, angio-oedema, food allergy, and urticaria) occurred in England between 1990-1 and 2000-1. This almost certainly reflects an increase in incidence.

Trends in admissions can reflect changes in health care; in disease labelling, coding, or recording; and in the underlying epidemiology of the condition. We were unable to assess the impact, if any, of changes in health seeking behaviour but believe it is a minimal source of bias in people admitted to hospital. Changes due to greater public awareness of the risks of allergic reactions or to better treatment cannot be ruled out, however; an eightfold increase in community prescriptions for allergic emergencies (adrenaline, BNF category 3.4.3) in this period may be evidence of this. ${ }^{5}$

We were unable to assess the accuracy of diagnoses. It seems likely, however, that any misclassification would have led to diagnostic transfer within the four disease areas under study. ICD-10 came into operation half way through the study period, but trends were broadly similar in the period $1990-1$ to $1994-5$ and 1995-6 to 2000-1 and showed little evidence of step changes.

A changing threshold of admissions is unlikely to have accounted for the findings observed, as no major new guidelines or recommendations for the management of allergic conditions were produced during this period. These increases could be caused by increasing exposure to environmental risk factors (such as peanuts and other foods or latex), to an increased susceptibility in the population to these allergens, or to a combination of these factors.

Contributors: All four authors were involved in drafting the study protocol, interpreting the results, and writing the paper. $\mathrm{RG}$ analysed the data and is the study's guarantor.

Funding: Project grant from the British Society of Allergy and Clinical Immunology. RG is supported by the Lung and Asthma Information Agency (funded by National Asthma Campaign, British Lung Foundation, and British Thoracic Society). A NHS/PPP primary care award supports AS.

Competing interests: None declared.

Ethical approval: Not needed.

1 European Allergy White Paper: allergic diseases as a public health problem. Braine-l'Alleud: UCB Institute of Allergy, 1997.

2 Sheikh A, Alves B. Hospital admissions for acute anaphylaxis: time trend study. BMJ 2000;320:1441.

3 Department of Health. Hospital episode statistics (Volume 1). London: HMSO, 1991.

4 World Health Organization. International classification of diseases:manual of the international statistical classification of diseases, injuries, and causes of death. London: HMSO, 1977.

5 Department of Health. Prescription cost analysis. www.doh.gov.uk/ prescriptionstatistics/index.htm (accessed 14 July 2003).

(Accepted 21 August 2003)

\section{One hundred years ago}

\section{The responsibility of surgeons and their fees B.c. 2300}

In the time of Hammurabi, King of Babylon, who lived 2,300 years B.C., the laws regulating the practice of surgery seem to have been rather uncomfortable. According to the code of laws of this monarch, discovered at Susa in 1902 by M. de Morgan, and transcribed and translated by Father Scheil, a surgeon who operated on any one with a bronze stylet or removed a film and saved an eye, was entitled to receive 10 shekels of silver. In the case of a noble the surgeon received 5 shekels, and for a slave 2 shekels. For setting a fracture in the case of a freeman he received 5 shekels, for the son of a noble 3 shekels, for a slave 2 shekels. These fees are doubtless large; but, on the other hand, the surgeon had to bear a somewhat onerous responsibility, for if, when operating with the stylet, he killed a freeman or caused the loss of an eye, his hands were to be cut off; if the slave of a noble died after a similar operation, the surgeon had to give a slave in return; if he caused the loss of a slave's eye, he had to pay half his value. Apparently the surgeon was charged with the duty of marking slaves; if a surgeon marked a slave as "inalienable" without the knowledge of his master, his hand was to be cut off; but if he was induced to do this by the deception of a third person, that person was to be killed and buried in his house, while the surgeon was set free on swearing that he did not perform the act knowingly. It is somewhat difficult to understand how it would be possible to exercise the profession of a surgeon under such laws. And yet the civilization in which they were enacted was one of long date and far removed from the primitive organization of society. Perhaps, like some legislation nearer home, they were not so formidable in reality as they appear on the statute book. In England a hundred years ago the law punished sheep stealing with death; but we know the result was not to hang sheep stealers, but to make it impossible to get a conviction.

(BMJ 1903;ii:211) 